\title{
The Brazilian Journal of Pulmonology and international databases
}

\section{O Jornal Brasileiro de Pneumologia e as bases de dados internacionais}

\section{Carlos Roberto Ribeiro Carvalho}

In an editorial published last year, we reported how proud we were of having been very wellranked by Thomson Reuters, which gave the Brazilian Journal of Pulmonology (BJP) an impact factor of 1.391.(1) This year, we were excluded from the Journal Citation Reports (JCR) list, published in June. This means that, temporarily, the BJP does not have a Thomson Reuters impact factor. However, an essential piece of information for understanding the current situation is that the BJP continues to be indexed in all major national and international scientific databases-SciELO, PubMed/MEDLINE, Scopus, and even the Institute for Scientific Information (ISI) Web of Science database-i.e., the Portuguese-language and English-language articles published by the BJP continue to be freely available, and the citations provided and received by them continue to be duly computed. This means that ours continues to be a journal with an international circulation.

In recent months, there has been a lot of information and misinformation in different media. In order to bring clarification to our associates, 1 will summarize the history of the current editorship of the BJP.

In December of 2010, after submitting an action plan to the Brazilian Thoracic Association (BTA), 1 was chosen to be the editor of the BJP for the next four years. Since then, 1 have attended a series of meetings with more than a hundred other editors of national and international journals, discussing how to improve the performance of our scientific journals. Several of these meetings were sponsored by the Brazilian Association of Science Editors, the Brazilian Medical Association and the Fundação de Amparo à Pesquisa do Estado de São Paulo (FAPESP, São Paulo Research Foundation). The SciELO model was created by FAPESP, in conjunction with the Latin American and Caribbean Center on Health Sciences Information, as well as national and international institutions related to scientific communication. The SciELO database has now been in existence for 15 years and has revolutionized the dissemination of research conducted in developing countries, being the pioneer in making articles openly accessible to the global scientific community at no cost. This model has now been recognized and replicated by numerous international organizations.

Over these two and a half years, 1 have attended meetings with a smaller number of editors (1 recall at least eight), in which we always discussed the best ways to internationalize our journals and organize our administrative staff, the choice of a publisher to help us with the internationalization, the choice of a company that would provide the best translations of articles into English, and the costs of journal publishing (print and online publication), as well as other issues, such as whether or not to charge researchers for publishing their manuscripts, obtaining other sources of funding (specifically, the Brazilian National Council for Scientific and Technological Development), changing the article submission system, giving more importance to our peer reviewers, improving the presentation of the results of studies conducted in Brazil (which have been increasing in quantity and quality), strengthening the journals in order to attract articles of higher quality, not only from Brazil but also from other countries. In none of the meetings 1 attended did we discuss any deliberate plan aimed exclusively at increasing the impact factor of the journals. What we did discuss was how to present the results of the studies conducted in Brazil more effectively.

Brazilian researchers habitually read scientific journals. That includes the major international generalist journals (e.g., the New England Journal of Medicine, Nature, Lancet, and Science) and the most important specialist journals in their chosen field (for researchers working in the respiratory field, that includes the American Journal of Respiratory and Critical Care Medicine, Thorax, the European Respiratory Journal, Chest, etc.). They do not necessarily read Brazilian journals that also might publish articles in their specialty, other than the journal of their respective professional societies; in the respiratory field, that would be the BJP, which is the only such journal in 
Brazil and only the second South American pulmonology journal to be indexed for the ISI database. Therefore, one of the actions discussed was that of soliciting review articles or editorials based on what we saw in the international literature and heard in lectures, including those given by international editors who attended the aforementioned meetings. By publishing such articles, we would be able to introduce Brazilian researchers to the scientific production coming out of Brazil, in their respective specialties, that was not available in the international journals or in the Brazilian journal published by their society. Obviously, in review articles, it would be possible to cite a large number of articles, which would also have a positive effect on the impact factor of the journals cited. The editors, together with their editorial boards, were free to decide whether or not to publish these articles and on which theme they would focus.

Another extensively discussed topic was selfcitation, given that it is a real problem for some Brazilian journals, although not for the BJP. This is an interesting point, speaking specifically of the BJP. As an editor, if 1 simply wanted to inflate the impact factor, 1 could publish articles (or editorials) commenting on themes discussed in previous years and published in the BJP, which would have much greater efficiency for the sole purpose of increasing the number of citations, given that the percentage of self-citations found in the BJP (datum available in the ISI and Scopus databases) does not exceed 20\%.

The e-mail sent by Thomson Reuters explaining the reason why the BJP was excluded from the 2013 list stated that the decision was based on the fact that an article published in the Journal of the Brazilian Medical Association ${ }^{(2)}$ contained a large number of citations to articles published in the BJP. The idea behind that article was to present a review of cardiorespiratory research in Brazil. However, since the major journal for the dissemination of research in the respiratory field in Brazil is the BJP, a little more than 80 of the 229 cited references were to articles in our journal, and, therefore, the Journal of the Brazilian Medical Association and the BJP were excluded from the JCR list in 2013.

Notice that the BJP was punished for having received citations from a single article published in another Brazilian journal. By doing a mathematical exercise, we estimate that, if we subtracted the citations to the BJP found in that article from the total number of citations to the BJP in 2011, our impact factor would experience a reduction of less than 20\% (decreasing from 1.39 to approximately 1.09). Recently, the Nature Journal blog discussed the matter and presented another review article, this one published in Clinics, also addressing cardiorespiratory research in Brazil. Although that article had not been considered anomalous by Thomson Reuters, the BJP was cited in it 52 times. Note that this number of citations results from the fact that the BJP is the major vehicle for the dissemination of pulmonary research in Brazil. In addition, as a mathematical exercise, if we also excluded those 52 citations, our theoretical impact factor would decrease to approximately 0.9 , which is still one of the highest among Brazilian journals indexed for the $\mathrm{ISI}$ database. This would keep the BJP in the same category (B2) in the journal ranking system of the Coordenação de Aperfeiçoamento de Pessoal de Nivel Superior (CAPES, Office for the Advancement of Higher Education) known as Qualis.

Now is the time when CAPES evaluates graduate programs for the three-year period 2010-2012, and, at the moment, the BJP is unlisted in the Qualis/CAPES system. We have talked to the evaluators and to those responsible for Medicine 1,11 , and 111 , explaining the situation. The BJP is the major vehicle for the dissemination of respiratory research in Brazil and concentrates most of the scientific production from national programs. We hope that the manuscripts published in this period will be considered in this evaluation. Although we are not on the 2013 JCR list (ISI database), we are in the Scopus database, which includes a larger number of journals. Scopus publishes an index known as "cites per document (2 years)", which uses the same methodology as that used to calculate the Thomson Reuters impact factor. Both indices have been accredited by CAPES since the evaluation of the previous three-year period, with the higher of the indicator values released by the two major companies that publish journal rankings (Scopus and ISI Web of Science) being used for the ranking. The SClmago journal ranking system (which uses the Scopus database) released its 2012 index in August. The BJP was assigned a rating of 1.15 , remaining consistent with Qualis category B2, the same as that of the previous year. It is of note that, in 2010 , before the evaluation of the previous 
three-year period, the editors of more than 50 Brazilian journals met with representatives of CAPES and expressed their concern regarding the overvaluation of a single rating index and regarding the Qualis list released at the time. They then suggested that "the qualitative analysis of Brazilian journals should be reevaluated and should not solely depend on the impact factor published by the JCR".(3)

Therefore, we hope that CAPES will not exclude the BJP articles from the scientific production of hundreds of Brazilian researchers who published the results of their research in our journal and that it will see the extent of this decision in the light of how out of proportion the event has been blown. By doing so, CAPES would be penalizing the journal (the official organ of the BTA, having been regularly published since 1975), as well as the researchers who carried out the protocols and published their results. 1 look forward to seeing the 2014 JCR list. All indications are that it will once again include the BJP. 1 hope it is clear that there was no bad faith by the editors; we have been working tirelessly to improve the quality of our journals.
The BTA Board of Directors has been informed of all of the facts and has been following these events. The BTA has given the BJP its full support. We are all united in our commitment to disseminate respiratory research conducted in Brazil. Although this is a delicate moment, it is important that we have the cooperation of our authors and reviewers during this period, so that we can maintain the high level of quality we have achieved in the BJP.

\section{Carlos Roberto Ribeiro Carvalho} Editor of the Brazilian Journal of Pulmonology

\section{References}

1. Carvalho CR, Baldi BG, Jardim CV, Caruso P. Publication of the impact factor of the Brazilian Journal of Pulmonology: a milestone on a long and arduous journey. J Bras Pneumol. 2012;38(4):417-8.

2. Patel KK, Caramelli B, Silva MR. Articles on the cardiopulmonary system recently appeared in Brazilian clinical and surgical journals. Rev Assoc Med Bras. 2011;57(6):717-38.

3. Andriolo A, Souza AF, Farias AQ, Barbosa AJ, França Netto AS, Hernandez AJ, et al. Classification of Journals in the QUALIS System of CAPES - URGENT Need of Changing the Criteria! Arq Bras Cardiol. 2010;94(3):271-2, 290-1. 